optician. The method, so far as I have been able to make it out as advertised, "Sight testing for the general practitioner," is on a level with that of the " honourable company" of spectacle sellers, being one which neglects spasm of the eye, and is on that ground to be condemned as likely to be unreliable if used to prescribe spectacles for young people. We now have our Board School children tested as to visual acuity, and errors of refraction become obvious as soon as young people go to work, so that glasses are becoming more necessary every day at earlier ages. The correction of the causes of the pain and inconveniences from refractive errors is part of a medical man's work and should not be allowed to pass into the hands of those who seem to be organising themselves into a vested interest; whilst at the rame time their methods for the reasons given above are daily becoming unsuitable and actually harmful to increasing numbers of their patients. I am, Sirs, yours faithfully,

JAMES KERR,

Honorary Surgeon to the Bradford Eye and Ear Hospital. Bradford, Nov. 22nd, 1898.

** We think the association will find our approval very modified.-ED. L.

\section{THE TREATMENT OF TETANUS BY ANTITOXIN.}

To the Editors of THE LANCET.

SiRS,-Mr. Stonham's case of tetanus recorded in THE LANCET of Nov. 19th is of much interest as a case of tetanus, but it could hardly be a matter of surprise that in so acute a condition the treatment with antitoxin should have failed. Every surgeon will, I think, agree that as a general rule the shorter the period of incubation in tetanus the more acute in all probability will be the course of the disease, and the greater the likelihood that whatever the treatment adopted the remedy will fail. It is in the chronic cases where the symptoms are delayed and are in themselves less severe that internal remedies, and antitoxin amongst them, have seemed to be of most use, but in all cases the suspicion may fairly be entertained that the disease might have passed away without them. But if antitoxin may seem to fail or to be of comparatively small value as a mode of treatment in the course of the disease it is possibly far otherwise when it is used as an immunising agent. Happily, I have not myself had a case of tetanus in my wards for many years, and the experience of other surgeons is doubtless the same, because of the care now taken in the cleansing of all wounds. I am unable, therefore, to speak from personal observation, but a great impression was made on my mind by a paper in the Annals of Shrgery of December, 1897, by Professor Dennis of New York on the Treatment of Tetanus. In speaking of antitoxin as an immunising agent he says: "All surgeons agree that it would not be justifiable to immunise a patient on the vague supposition that tetanus might develop. The use of the antitoxin as a prophylactic measure is consequently limited to those cases where the wound has been inflicted in such a manner as to allow garden-earth, plaster from walls, or manured soil to come in contact with it, or where the traumatism has been caused by a rusty nail upon which the bacilli are discovered, or in a given locality where tetanus is prevalent, or where the wound is a lacerated one with entrance of foreign bodies into it." And then, having referred to the marvellous prophylactic influence of the diphtheria antitoxin, he goes on: "If such results follow from the use of antitoxin as an immunising agent in diphtheria it is logical to expect that even more brilliant results will ensue in the adoption of this treatment in tetanus, since the antitoxin of tetanus shows even better results in lower animals. Under such conditions immunisation is a proper line of treatment and one from which success is sure to follow. Bazy, a French surgeon, had 4 fatal cases of tetanus in his practice in one year and subsequently began injecting 20 c.c. of serum into all patients who suffered from lacerated wounds into which extraneous matter had of necessity entered. Since he adopted this practice tetanus has not followed in those cases in which a strong probability existed that this dreaded disease might develop. Lambert mentioned that Nocard in veterinary surgery immunised 375 animals and in no single case did tetanus develop, while he had 55 cases of the disease in animals in the same environment."
It is open, of course, to everyone to question the value of evidence like this, where the prediction of tetanus might never have been verified, but the evidence, to say the least, is very striking. It is, moreover, in accordance with all that is known of the disease itself and of the behaviour of antitoxins in general to draw the conclusion that the antitoxin of tetanus is more likely to succeed in warding off the disease altogether than in arresting or putting an end to it when the symptoms have developedthat really is to say when the mischief has been done. In recording a case of hydrophobia in THE LANCET of Feb. 8th 1890, where opium and eserine had been pushed to their physiological effects without result, I wrote: "The fact of the matter, however, is this : that at that period of the disease no drug treatment can be of the least avail to stay the progress of the effects which the specific poison of rabies has wrought in the most vital parts of the nervous system. The antidote must begin its work at an early period and no unprejudiced mind can doubt that that is to be found in the inoculations of M. Pasteur." Immunisation against hydrophobia, a very similar malady, has long been above question. I would urge the like treatment in the case of tetanus whenever there is reasonable ground for fearing that it may arise. I cannot help thinking that the antitoxin will then be proved of greater value than the record of cases treated by it up to this time seems to warrant.

Nov. 22nd, 1898

I am, Sirs, yours faithfully, Herbert W. PAgE.

\section{"PH A R Y N G O - M Y COSI S." \\ To the Editors of THE LANCET.}

SIRS,--The attention which has been drawn to the subject of this disease, as treated of in Dr. Lubet-Barbon's work on the subject and reported in your columns, ${ }^{1}$ is extremely well deserved, if we may judge by the alarm which is experienced when its presence is accidentally discovered-an alarm which is absolutely uncalled for. From a consideration of the histology of the condition I have been led to adopt a plan of treatment to which no reference is made in your report-namely, the application of salicylic acid which is known to have so marked an effect in breaking up and destroying masses of cornified epithelium. The opportunities for treating such cases are not common, but I have found this remedy more effective than any other. The mode of use is to twist a very thin layer of cotton-wool on the tip of a fine bent probe. This is dipped in a 25 per cent. solution of salicylic acid in alcohol and is then applied to each spot of pharyngo-mycosis. In the intervals the patient may apply a 5 per cent. solution in rectified spirits to which a small proportion of glycerine is added. Although I hit upon this method of treatment without suggestion from elsewhere I understand that it has already been employed by Spengler. I recommended the remedy to my friend Dr. Herbert Tilley, and was gratified to find that his experience of its use was as favourable as my own. ${ }^{2}$ I may add that I have employed the remedy in cases of recurring papilloma of the larynx with most satisfactory results, and I believe that even in pachydermia of that organ I have obtained by its use beneficial results such as no other treatment at my hands has brought about. I have great expectations as to the value of salicylic acid in various diseases of the throat.

I am, Sirs, yours faithfully,

Upper Wimpole-street, W., Nov. 21st, 1898. DUNDAS GRANT.

\section{"AGORAPHOBIA."}

To the Editors of THE LANCET.

SIRs,-After reading the very interesting article on agoraphobia written by Dr. Headley Neale in THE LANCET of Nov. 19th I would like to draw attention to symptoms which he would doubtless attribute to agoraphobia that are referred to in a recent publication, "The Secret of Good Health and Long Life" (Bowden), but which I consider belong to acute "tea-poisoning." I am not one who wonld consider that agoraphobia is "all bosh" exactly, but I have found some of the very characteristic symptoms

1 The LANCET, Nov. 12th, 1898.

2 Proceedings of the London Laryngological Society, May 11th, 1898. 